\title{
Image, Aesthethic and Tourism in postmodern times
}

\author{
Maximiliano E. Korstanje* \\ Guest Editor \\ University of Palermo Argentina \\ International Society for Philosophers, United Kingdom
}

The present special issue was a personal challenge because the existent maturity of research respecting to destination image was evident. Over years of investigation a valuable conceptual framework was accompanied with high-quality empirical studies. Nonetheless, image should not be circumscribed to the perceptual traits perceived from destinations. There are many forms of images that have not been explored. Following this reasoning, I posed the theme of image to be developed from an interdisciplinary field ranging from psychology to anthropology, from management to geography and so forth.

Image plays a pivotal role in the configuration of tourism beyond what can be said on the attractiveness of a destination. And this happens because image is an important facet of human life that not only is limited to the ocular-centrism. The Greek legacy posed a serious question respecting to how the image is constructed, and of course perceived for reminded. Symbolically, the presence of founding parents was of paramount importance to illuminate communities in turbulent times. In ancient times, some tribes crafted masks of their ancestors so that their legacy not to be lost. Whenever a king dies, some communities copied his/her face in a mask. This master-work served as a religious and political instrument of indoctrination to gain further legitimacy. As the previous argument given, image and death seems to be inextricably intertwined. Nowadays, things seem to be changed a bit. These relics have been stored at museums and technologies facilitated the times and efforts to design landscapes and experience. The world of photography sets the pace to a new revolutionary way of creating digital landscapes from a PC terminal. As a social construe, image represents our attempt to control not only the time, but also the life. One might speculate that many tourist destinations have made from their image their primary resource to success. Undoubtedly, image and aesthetic are of paramount importance to grant the growth of this industry. Tourist destinations appeal to create a meaning, and this meaning evokes an image. Understanding how this image is built and negotiated, we would expand how in diverse contexts tourism works.

As above noted, a discussion of image not only should be limited to what can be seen, interesting research has recently conducted in anthropological field respecting to other additional

* Korstanje is associate professor of Tourism at Palermo University and researcher of International Society for Philosophers, Sheffield UK and Editor in chief of the first journal dedicated to safety in tourism and hospitality (International Journal of Safety and Security in Tourism/Hospitality). With more than 500 peer-reviewed papers and 20 books published in the field of tourism, risk, disaster-studies and mobility he takes part of 20 specialized journals as editorial board member. In 2012 earned the award to excellence given by Emerald Publishing group *UK by the performance as outstanding reviewer of the International Journal of Disaster Resilience and Built Environment - which is hosted University of Salford. In 2013 earned the same award for the Journal of Place Management Manchester Metropolitan University. Besides this recognition, Korstanje was nominated to three honorary doctorates for his achievements and contributions in the field of tourism. 
themes such as patrimony, heritage, sustainability, development, literature, customer loyalty, branding, event-management, governance, risk, modernity, movies, cultural entertainment, technology-TICS, and so forth. Most likely, in these digital times, the camera captivates and puts events in any corner of the globe in minutes, but this acceleration generates a great dependency of the media. Any event, whatever its nature, does impact on tourism ... Policy makers and governments devote considerable time and spend money in designing the image of tourist destination, but their failure depends on the lack of uncertainty of how it evolves. More important, we strongly believe in the needs to open a new debate in tourism-studies to expand the current understanding of image from an interdisciplinary viewpoint.

Readers who want to inspect this volume will find the paper of Geoffrey Skoll who traces the role of arts preventing the alienation of spaces in the process of gentrification in Riverwest city, US. Capital in post modern times has been expanded to the extent to make from consumers consumed goods. This is exactly the point addressed by Korstanje and Tarlow in the second paper. Authors recognize that disasters, such as the quake whipped Japan a couple of years back, may be commoditized to provide a message to a broader audience. In context of disasters, nationalism arises in order to avoid the identity to be fragmented. Mass-death and suffering wake up the best of our instincts to strength the social bond. The problem is that sometimes this is manipulated by the mass media.

As the previous backdrop, Juan Carlos Monterrubio presents a valuable research where the key factors that influence in the formation of organic image are analyzed. Based on the precautionary principle of warning, he examines the connection of risk, image and attractiveness. Babu George, Tony Henthorne, Alvin Williams place the contributions of S. Plog under the lens of scrutiny. The outcome of this work shows that even if allocentric tourists prefer for nascent destinations, others in the end of the cycle are chosen too. The philosophical sense of image and aesthetic is given by Maximiliano Korstanje to expand the current understanding of Immanuel Kant's account. Rather, R. Rajesh developed a dichotomy between destination image and tourist satisfaction. Equally important, four key factors are introduced in the formation of destination image: tourist perception, infrastructure, satisfaction, and loyalty. Shorter but no less important, the notes authored by
Margarita Barretto not only shows why she is still the most prominent lucid mind in tourism, but also combines the sociological view of $\mathrm{W}$. Benjamin with studies of mobility as John Urry and D. Maccannell. She insists in finding the anthropological roots for tourist-consciousness beyond the hegemony of any discipline.

I strongly recommend the eighth manuscript, where Agustin Santana Talavera explains that attractiveness depends on the previous development of image-distinction. The existent specialized literature, Santana adds, seems to be focused on the process of image-control. This work discusses the benefits and limitation of such a view-point. By the way, Matthew Smith ad Ericka Amorim argue that the attractiveness of tourist destinations are determined by the aesthetic factors but further investigation is needed on the dilemma the industry poses. At some extent, policy makers devote considerable attention to the factors that attract people but at the same time, this saturates the landscape. Questions of risk perception and crisis management are widely managed by Bingjie Liu, Lori Pennington-Gray and Ashley Schroeder. If we, as analysts, understand the psychological effects on risk over destination, we will strength the existent capacity of mitigation to avoid serious damage to the destination. Past travel experience is of paramount importance to build predictors of crisis.

Over years, the constructing of romantic gaze has been prioritized in Europe and Western civilization. Susana Gastal unearths the legacy of Roland Barthes to re-visit the social and economic factors that form the landscape. As a social construe, landscapes signal to the hospitality and welcoming garden. In view of that, Gastal finds the roots of modern tourism in the romantic texts and pictures of XIXth century.

Dolors Vidal Casellas, Silvia Aulet Serrallonga and Neus Crous Costa exhibit the potentiality of Catalonia to offer religious tourism. What seems to be important to debate here is the connection between cultural heritage and branding logic. Evidently, though government has struggled to pose Catalonia as heritage destination, a growing segment of demand linked to religion is surfacing. This poses a good question on how organic image is formed. Top-down policies sometimes are not enough, as researchers our duty is to know why.

Jaime Alvarez de la Torre and Diego Rodriguez Toubes Muñiz delve into the current positive stereotypes on Brazil based on egalitarianism and happiness. Nonetheless, negative assets as 
insecurity, crime and violence have not declined in the social imaginary of tourist-delivering countries. To balance the coherent adequacy of the country as venue of the next World-cup and Olympic Games, it is necessary the articulation of an all encompassing plan of risk-reduction. Unless otherwise resolved, Brazil's image would be negatively affected. Last but not least, Olga Araujo Perazzolo, Marcia Maria Capellano Dos Santos and Luciane Todeschini Ferreira develop a psychological model to understand image. The pleasure -and displeasure- as emotional drives alter the frames of perception to produce specific Mnemic records. The importance of tourism as a social activity is not given by business but its hospitable nature and success to re-signify the sensoriality of tourists. This research stimulates a hot discussion on tourism epistemology simply because it considers the self in the quest of disrupting events to inspire discovery but at the same time returning to the secure-place of hospitality.

The fourteen papers gathered for this issue consist in high-quality approaches that deal with the aesthetic nature of leisure and tourism. First and foremost, I would like to thank Editor in Chief Agustin Santana Talavera who kindly invited me to take part of this project but this would never have been possible without the participation of authors, who have made a substantial contribution that will initialize the debate in next years. Let me clarify though the language in this special issue is English, we respected other texts, because of their academic profundity, in other language as Portuguese and Spanish. Certainly, we feel that the issue should remain in its original version. 